\title{
STRATEGI INDUSTRI KECIL MENENGAH KOMPONEN OTOMOTIF (STUDI KASUS PT PQR)
}

\section{INDUSTRIAL STRATEGY FOR SMALL MEDIUM ENTERPRISES IN AUTOMOTIVE COMPONENTS INDUSTRY (CASE STUDY IN PT PQR)}

\author{
Dian Rinaldy ${ }^{* 1}$, Alla Asmara ${ }^{* *}$, dan Muhammad Findi**) \\ ${ }^{*}$ Sekolah Bisnis, IPB University \\ Jl. Raya Pajajaran Bogor 16151 \\ **) Departement Ilmu Ekonomi, Fakultas Ekonomi dan Manajemen, IPB University \\ Jl. Agatis Kampus IPB Darmaga, Bogor 16680
}

\begin{abstract}
This study analyzed $P T P Q R$ 's external conditions and strategic factors that arose, analyzed $P T P Q R$ 's internal conditions, formulated alternative strategies for $P T P Q R$, and determined strategic priorities for PT PQR. The strategic planning phase began with an external analysis that developed with a PEST analysis and Porter's Five Forces. Later on, we performed an internal analysis. The strategic business planning performed I-E and TOWS matrices and the Quantitative Strategic Planning Matrix (QSPM). The external analysis results identified growth, customer loyalty, and ATPM competition as opportunities, while exchange rate fluctuations, import policies, and newcomer meetings were the challenges. The internal analysis results found product quality, competitive selling prices, and production capacity as the strengths, while low productivity, workplace accidents, and the quality of human resources were identified as weaknesses. The IE matrix combined IFE value of 2,346 and EFE value of 2,178 to position $P T P Q R$ in quadrant $V$. Therefore, the strategy was to hold and maintain. The eight alternative strategies for PT PQR were product development strategy, market development, improvement in production management, HR development, Quality management implementation, development of higher capacity machines, inventory management, and improvement of Production Operation Standards (SOP). Market development strategies with new ATPM market development and product development strategies with diversified furniture products were two priority strategies that were complemented by short and long term action plans in implementing these strategies.
\end{abstract}

Keywords: PEST analysis, IKM, EFE, IFE, Matriks IE, Matriks TOWS, QSPM

\begin{abstract}
Abstrak: Penelitian ini bertujuan menganalisis kondisi eksternal PT PQR dan faktor strategis yang timbul, menganalisis kondisi internal PT PQR, merumuskan alternatif strategi bagi PT PQR, serta menentukan prioritas strategi bagi PT PQR. Tahap perencanaan strategis diawali dengan analisis eksternal yang dikembangkan dengan analisis PEST dan analisis industri menggunakan Lima Kekuatan Porter lalu diikuti analisis internal. Sementara untuk merancang strategi bisnis digunakan matriks I-E dan matriks TOWS dengan Quantitative Strategic Planning Matrix (QSPM). Hasil analisis eksternal mengidentifikasi pertumbuhan permintaan, loyalitas pelanggan, dan persaingan ATPM sebagai peluang sementara fluktuasi nilai tukar, kebijakan impor, dan kehadiran pendatang baru adalah ancaman utama. Hasil analisis internal mengidentifikasi kualitas produk, harga jual yang kompetitif, dan kapasitas produksi adalah kekuatan utama, sementara produktivitas rendah, kecelakaan di tempat kerja, dan kualitas sumber daya manusia sebagai kelemahan. Matriks IE memadukan IFE 2,346 dan EFE 2,178 untuk memposisikan PT PQR dalam kuadran V dan rekomendasi strategisnya adalah pertahankan dan pelihara. Delapan alternatif strategi bagi PT PQR adalah strategi pengembangan produk, pengembangan pasar, perbaikan dalam manajemen produksi, pengembangan SDM, penerapan manajemen Mutu, investasi mesin berkapasitas lebih tinggi, pengelolaan inventori, dan peningkatan Standar Operasi Produksi (SOP). Strategi pengembangan pasar dengan memasuki pasar ATPM baru dan strategi pengembangan produk dengan diversifikasi produk furnitur adalah dua strategi prioritas yang dilengkapi dengan rencana tindakan dalam jangka pendek dan panjang untuk mengimplementasikan strategi-strategi tersebut.
\end{abstract}

Kata kunci: Analisis PEST, IKM, EFE, IFE, Matriks IE, Matriks TOWS, QSPM

\footnotetext{
${ }^{1}$ Corresponding author:

Email: rinaldy_dian@cat.com
} 


\section{PENDAHULUAN}

Industri otomotif di Indonesia adalah salah satu industri yang berkembang pesat, khususnya pada jenis kendaraan roda empat. Sepanjang tahun 20102016, angka produksi maupun penjualan mobil jenis penumpang maupun komersial cenderung meningkat (Gaikindo, 2017). Sejalan dengan pertumbuhan kapasitas produksi dari para Agen Tunggal Pemegang Merek (ATPM) dalam memenuhi permintaan pasar dalam negeri maupun eskpor, maka pertumbuhan industri komponen otomotif sebagai pendukung utama bagi produksi mobil juga semakin meningkat dengan bertumbuhnya pasar domestik dan meningkatnya potensi pasar kelas menengah (Kemendag, 2014).

Gambaran rantai pasok dalam industri otomotif menurut Smitka (1989), adalah seperti piramida, di mana perusahaan ATPM sebagai puncaknya, ditopang perusahaan-perusahaan pembuat komponen otomotif pada tingkatan yang disebut Tier-1, Tier-2, dan Tier-3. IKM komponen otomotif berada pada Tier-2 atau Tier-3 untuk menyokong perakit komponen semifinished pada Tier-1 diatasnya. Jumlah perusahaan dalam industri otomotif Indonesia diprediksikan terdiri dari 20 perusahaan ATPM yang didukung oleh sekitar 550 perusahaan dalam lingkup Tier-1, dan lebih dari 1000 perusahaan dalam lingkup Tier-2 dan Tier-3 yang memproduksi komponen-komponen yang dibutuhkan (Kemenperin, 2016).

Industri Kecil Menengah (IKM) memiliki peranan amat penting di Indonesia. Pada tahun 2016 IKM dan UMKM menyumbang PDB sebesar $60 \%$ atau setara 520 triliun rupiah. Sementara itu dalam sektor industri non migas, subsektor industri otomotif atau alat angkutan menyumbangkan kontribusi sebesar 10,47 \% terhadap PDB (Kemenperin, 2017). Sektor otomotif adalah salah satu Industri Unggulan dalam Rencana Strategis Kementerian Perindustrian Tahun 2015-2019.

IKM komponen otomotif sangat bergantung pada strategi bisnis dari perusahaan ATPM, yang dalam kasus Indonesia, pangsa pasarnya dikuasai oleh perusahaan Jepang (Gaikindo, 2014). Diterapkannya "Keiretsu" atau kemitraan, aliansi atau perusahaan yang diperluas (Schonberger, 1982) oleh perusahaan ATPM terhadap para pemasoknya adalah ditujukan untuk hubungan jangka panjang yang stabil (Takeishi dan
Noro, 2017). Termasuk juga Target Cost Management, yang dilakukan perusahaan-perusahaan otomotif Jepang sejak 1963 untuk menentukan harga jual dari para pemasok agar harga jual produk kendaraan juga bisa lebih memberikan profit margin yang lebih besar (Feil et al. 2004; Baharudin dan Jusoh, 2015). Bagi IKM komponen otomotif, penurunan harga adalah tantangan besar, di saat yang sama pelanggan mudah untuk memilih untuk berpindah ke pemasok lainnya yang mampu memenuhi target harga yang ditentukan (Monden dan Hamada, 1991).

Dalam industri otomotif, terbentuk pola pasar monopsoni di mana perusahaan-perusahaan maupun IKM dalam rantai pasok otomotif hanya melayani satu pelanggan yang mendominasi kapasitas produksinya, sehingga timbul ketergantungan. Block dan Barnett (2009) menyatakan bahwa ciri pasar monopsoni adalah harga dan kuantitas barang atau jasa ditentukan ketika hanya ada satu pembeli. Rantai pasok dalam otomotif dari mulai pembuat suku cadang mobil hingga perakitnya berada di bawah pengawasan perusahaan ATPM multinasional. Misalnya Astra International sebagai pemain utama di industri otomotif Indonesia berada dibawah pengawasan Toyota Motor Corps dari Jepang (Wicaksono dan Priyadi, 2016). IKM jelas menghadapi permasalahan keterbatasan modal, sumber daya manusia, pemasaran, dan rendahnya produktivitas (Tambunan, 2008).

Hubungan antara pelanggan dan pemasok dalam idustri otomotif mengedepankan hubungan kontrak jangka panjang dan saling ketergantungan yang tinggi, tetapi harga masih digunakan sebagai kriteria utama dalam pemilihan pemasok komponen otomotif, dan sangat tergantung pada karakteristik pemasok, penguasaan teknologi, kapasitas produksi, dan kualitas (Vanalle dan Salles, 2012). Tren dalam industri otomotif saat ini memperlihatkan terus munculnya pendatang baru dan semakin ketatnya persaingan di tengah menurunnya penjualan. Hal ini mendorong perusahaan otomotif untuk terus berupaya menurunkan biaya operasi, mempertahankan pangsa pasar, mempertahankan profitabilitas, dan mempromosikan nilai pelanggan (Nunez, 2007). Oleh karena itu, kebijakan-kebijakan dan aktivitas-aktivitas mereka dalam tujuan tersebut tentunya sangat mempengaruhi para pemasok di dalam rantai pasok mereka, termasuk hingga IKM-IKM komponen otomotif. 
Penelitian ini menitikberatkan pada analisis strategi bagi IKM Komponen Otomotif yang berbahan dasar logam. Beberapa penelitian sebelumnya mengenai IKM diantaranya mengenai strategi optimum pemanfaatan sumberdaya terbatas (Purwantoro, 2016), daya saing IKM (Setyawan et al. 2015) dan perencanaan strategi bisnis UKM Otomotif berbahan dasar karet (Katuruni, 2015). Adapun terkait metode, penelitian ini menggunakan Analisis Eksternal / Internal dan Analisis SWOT (Vidiansyah 2013; Rahman et al. 2012), Analisis Eksternal dan Analisis Internal menggunakan matriks IFE, matriks EFE, dan pada tahap pemaduan dengan Matriks IE dan matriks TOWS, dilanjutkan dengan metode QSPM (Dianawati, 2003), Analisis PESTEL dan Analisa industri dengan Lima Kekuatan Persaingan (Rahman et al. 2012).

Dalam literatur internasional terdapat penelitian mengenai industri otomotif, diantaranya kaitan UKM otomotif dalam rantai suplai ATPM (Lin, 1994; Anggoro, 2015), kinerja manufaktur UKM Otomotif dan pengaruhnya terhadap daya saing (Amrina dan Yusof, 2010), strategi manufaktur dan kinerja unggulan kualitas, ketepatan waktu pengiriman, fleksibilitas dalam proses produksi, dan biaya (Laosirihongthong dan Dangayach, 2005), dan strategi defensif UKM dalam menghadapi tekanan eksternal seperti resesi ekonomi, persaingan, kebijakan mengenai perpajakan, tingkat bunga dan ketersediaan pinjaman (Lawrence, 2012), serta kemampuan inovatif dalam industri otomotif sebagai kompetensi inti (Vermak dan Steyn, 2014). Berbagai penelitian mengenai strategi yang diterapkan oleh UKM dan kaitannya terhadap kinerja perusahaan diantaranya adalah strategi efisiensi biaya dan strategi diferensiasi produk serta kombinasi dari strategi tradisional tersebut dengan diiringi penerapan teknologi modern dan praktik manajemen seperti manajemen mutu dan teknologi produksi (Leitner dan GudenBerg, 2010) dan strategi kepemimpinan UKM untuk fleksibel menanggapi permintaan pasar, aktivitas yang dilakukan oleh para pesaing, serta perubahan lingkungan (Samitowska, 2011).

Penelitian ini menggunakan pendekatan studi kasus untuk menganalisa strategi dengan tiga tahapan yaitu tahapan input, tahapan pemaduan, dan tahapan penentuan strategi (David, 2013), didahului analisa industri (Porter, 2008) dan analisa eksternal dan internal (Wheelen dan Hunger, 2012). Studi kasus pada penelitian ini dilakukan pada PT PQR, salah satu IKM yang memproduksi komponen otomotif bagi perusahaan
Tier-2 untuk ATPM Daihatsu dan Toyota. Sejak tahun 2012 PT PQR memproduksi pin besi untuk sandaran kepala (headrest) pada jok mobil berjenis MPV seperti Xenia, Avanza, Rush, Terios, Ayla, serta Agya. Pelanggan bagi PT PQR adalah PT TOS yang membuat headrest dengan chromium plating, yang menyuplai perusahaan Tier-1 yang membuat seat atau jok mobil. Memasuki tahun 2015 akibat krisis ekonomi global, perusahaan ATPM menurunkan produksinya hingga 3040\%. Imbasnya dalam kurun waktu 2014 hingga 2017, PTPQR mengalami penurunan pendapatan hingga $35 \%$. Menghadapi berbagai tantangan sebagai perusahaan yang sedang berkembang, PT PQR membutuhkan strategi bisnis yang lebih baik untuk mengembalikan kinerja serta meningkatkan daya saingnya di tengah kompetisi yang semakin ketat.

Penelitian ini bertujuan menganalisis kondisi eksternal PT PQR dan faktor strategis yang timbul berupa peluang dan ancaman bagi perusahaan, menganalisis kondisi internal PT PQR dan mengidentifikasi kekuatan dan kelemahan perusahaan, merumuskan alternatif strategi bagi PT PQR untuk meningkatkan daya saing dalam bisnis komponen otomotif, serta menentukan prioritas strategi bagi PT PQR dan menjabarkannya kedalam rencana tindakan perbaikan.

\section{METODE PENELITIAN}

Penelitian dilakukan di PT PQR yang berlokasi di Cileungsi Bogor pada bulan Juli hingga Desember 2018. Penelitian dilakukan dengan metode deskriptif. Data yang digunakan adalah data primer dan data sekunder. Data primer diperoleh dari hasil observasi, wawancara mendalam, dan pengisian kuesioner oleh para responden yang dipilih secara sengaja (purposive sampling technique) yang berada dalam rantai pasok PT PQR, yaitu terdiri dari pimpinan perusahaan serta pihak eksternal seperti pelanggan, pemasok, dan asosiasi industri kecil menengah, dengan keyakinan bahwa para responden memiliki pengetahuan akan kondisi PT PQR dan industri komponen otomotif, sehingga mampu menilai perusahaan secara objektif dan menyeimbangkan peniliaian dari responden internal. Data sekunder diperoleh dari Badan Pusat Statistik, Kementerian Perindustrian, dan sumber data lainnya yang relevan dengan topik penelitian seperti jurnal ilmiah, buku, proceeding, working paper dan lainnya. 
Tahapan penelitian meliputi analisis kondisi eksternal dengan analisis industri dengan model Lima Kekuatan (Porter, 2008) dan analisis PEST, lalu analisis kondisi internal dan dilanjutkan dengan alat analisis berupa matriks IFE (Internal Factor Evaluation) dan matriks EFE (External Factor Evaluation). Pemberian bobot berdasarkan metode Paired Comparison (Kinnear dan Taylor, 1996). Pada tahapan pemaduanmaka dirumuskan alternatif strategi dengan menggunakan alat matriks IE dan matriks TOWS. QSPM akan digunakan dalam langkah penentuan prioritas strategi, diikuti rencana penerapan strategi dengan metode Nominal Group Technique (Huge dan Mukherjee, 2018). Perusahaan perlu untuk mempertimbangkan semua bagian dari strategi secara menyeluruh dan tidak terpisah atau berdiri sendiri sehingga saling bertentangan, seperti misalnya strategi dalam penentuan harga dengan strategi pengembangan produk, atau dengan strategi meningkatkan kapasitas produksi (Hambrick dan Frederickson, 2011).

Kerangka pemikiran penelitian dapat dilihat pada Gambar 1, dimulai dengan menjabarkan permasalahan yang dihadapi PT PQR yaitu keuntungan semakin menurun, di saat yang sama persaingan semakin meningkat dan daya saingnya malah menurun.
Tahapan pemindaian lingkungan internal dan eksternal untuk mendapatkan faktor-faktor strategis seperti kekuatan, kelemahan, peluang, dan ancaman akan menjadi dasar penentuan strategi-strategi alternatif untuk meningkatkan daya saing perusahaan, hingga akhirnya penentuan strategi prioritas digunakan untuk merumuskan aktivitas-aktivitas penerapan strategi dalam jangka pendek dan jangka panjang.

\section{HASIL}

\section{Kondisi Ekternal PT PQR}

Analisis industri terhadap IKM komponen otomotif mendapati intensitas persaingan dalam kategori sedang, terlihat dari kelima variabel persaingan hanya satu variabel yaitu ancaman pendatang baru yang teridentifikasi dalam kategori intensitas persaingan yang tinggi, dengan total skor 3,221 dan oleh karenanya dapat dikategorikan sebagai ancaman bagi IKM komponen otomotif termasuk PT PQR, dan menjadi salahsatu tambahan atas faktor strategis eksternal yang dapat dikaji. Empat variabel lainnya berada pada total skor di bawah 3,0. Hasil Analisis Industri terlihat pada Tabel 1.

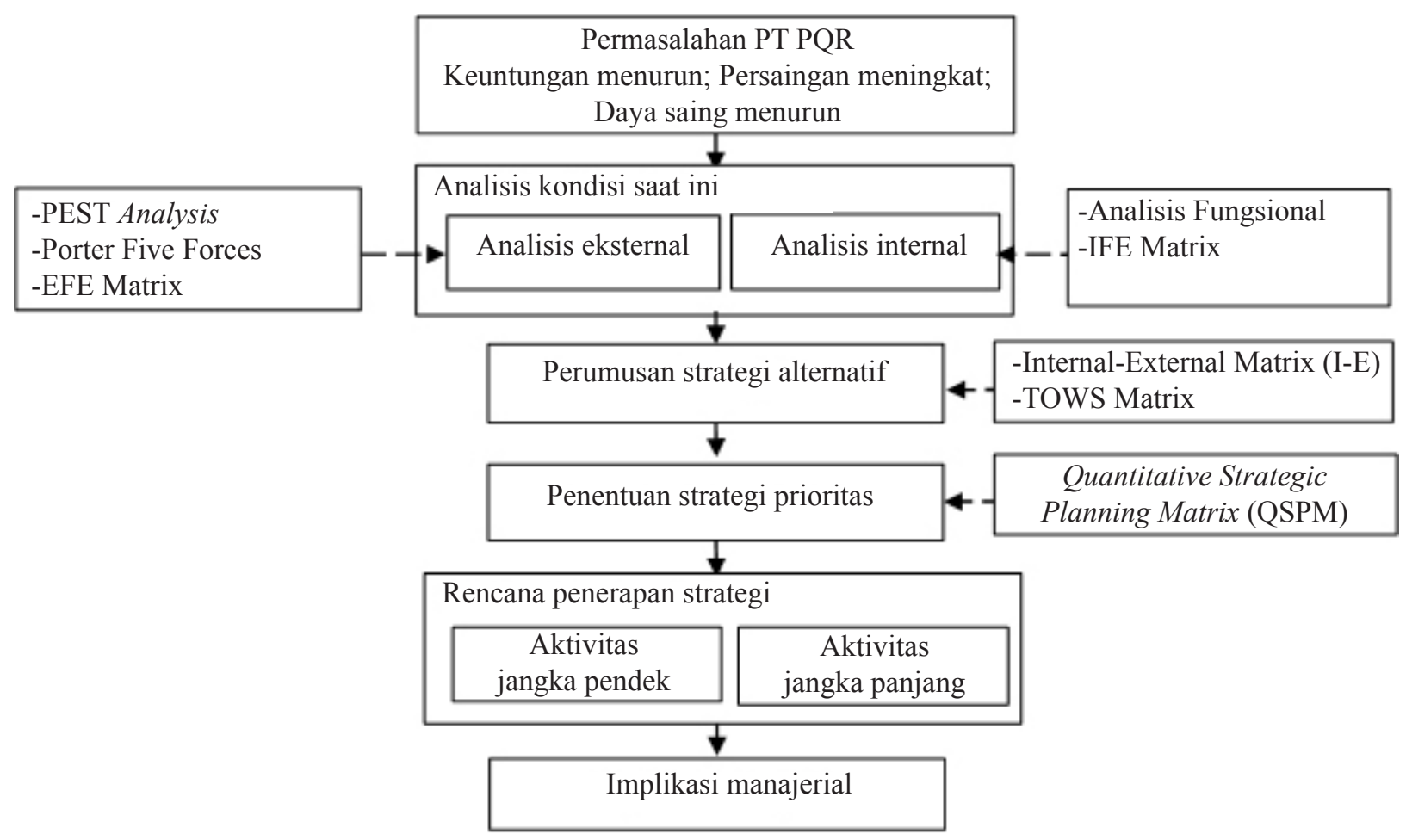

Gambar 1. Kerangka pemikiran penelitian 
Tabel 1. Hasil analisis industri berdasarkan lima kekuatan Porter

\begin{tabular}{lccc}
\hline Variabel & Total Skor & Intensitas Persaingan & Ranking \\
\hline Ancaman Pendatang Baru & 3,221 & Tinggi & 1 \\
Persaingan dalam Industri & 2,848 & Sedang & 2 \\
Ancaman Produk Pengganti & 2,785 & Sedang & 4 \\
Kekuatan tawar menawar pemasok & 2,572 & Sedang & 5 \\
Kekuatan tawar menawar pembeli & 2,840 & Sedang & 3 \\
\hline
\end{tabular}

Melalui Analisis PEST, pada aspek politik dan hukum yang paling berpengaruh dirasakan adalah kebijakan dan aspek hukum mengenai PMA yang merambah ke kelas IKM. Perangkat kebijakan yang mendukung tumbuhnya IKM-IKM baru yang berbasiskan PMA ini adalah diantaranya:

1. UU No. 25 Tahun 2007 tentang Penanaman Modal, pada pasal 5 dan pasal 12 menegaskan bahwa Indonesia membuka peluang bagi PMA, bentuk badan usahanya harus perseroan terbatas dengan bidang usaha yang memperhatikan perlindungan terhadap UMKM.

2. PP Nomor 17 Tahun 2013, tentang pelaksanaan UU No. 20 Tahun 2008 tentang UMKM. Pasal 25 disebutkan bahwa UMKM lokal dapat melakukan kemitraan usaha dengan Usaha Besar maupun Usaha Menengah asing melalui pola usaha patungan (joint venture).

3. PP No.44 Tahun 2016, tentang daftar bidang usaha yang tertutup dan bidang usaha terbuka dengan persyaratan, bagi penanaman modal. Industri komponen dan perlengkapan kendaraan bermotor roda dua dan tiga dinyatakan sebagai terbuka bagi PMA dengan persyaratan. Satu-satunya persyaratan mengenai praktek bisnis ini adalah diharuskannya kemitraan dengan pengusaha lokal.

Di satu sisi pemerintah bersikeras bahwa keberadaan dan pertumbuhan IKM-IKM baru sangat dibutuhkan karena industri otomotif Indonesia mengalami keterbatasan pasokan (shortage of supply), tetapi disisi lain ini meningkatkan persaingan dengan IKM-IKM lokal yang masih kesulitan. Pada periode 2010-2014 realisasi investasi untuk sektor industri pengolahan non-migas didominasi oleh PMA, sebesar Rp465,6 triliun atau $65,57 \%$ dari total investasi di sektor industri tersebut, di mana industri logam, mesin dan elektronik menyumbang Rp119,59 triliun dan industri kendaraan bermotor dan alat transportasi Rp85,84 triliun (Kemenperin, 2017). Dalam aspek ekonomi nilai tukar rupiah menjadi salah satu aspek yang paling dirasakan oleh para pelaku IKM komponen otomotif. Harga bahan baku kawat baja yang dibutuhkan PT PQR, yaitu baja Assental atau shafting bar JIS G3101SS400 terus meninggi dalam kurun waktu 3 tahun terakhir mengikuti kenaikan nilai tukar rupiah, seperti terlihat pada Gambar 2.

Aspek sosial yang berkaitan dengan IKM adalah iklim usaha (Purwaningsih, 2015). Iklim usaha dalam industri otomotif Indonesia sangat dipengaruhi oleh perusahaanperusahaan multinasional berskala besar, karena seluruh rantai pasok dari mulai pembuat suku cadang mobil hingga perakitnya berada di bawah pengawasan perusahaan ATPM multinasional. Seringkali kebijakankebijakan dari ATPM seperti pembatasan harga dan penurunan harga, membuat IKM yang berada pada Tier 2 dan Tier 3 sangat kesulitan. Penguasaan teknologi dalam empat aspek, yaitu kemampuan operatif, akuisitif, suportif, dan kemampuan inovatif bagi IKM komponen otomotif masih rendah (Suprihatini dan Maarif, 2015). Sementara transfer teknologi yang diharapkan dari ATPM saat ini baru berfokus pada perakitan, dan tidak berpengaruh pada peningkatan daya saing perusahaan penyokongnya (Wicaksono dan Priyadi, 2016).

Berdasarkan alat uji analisis PEST diperoleh bahwa politik luar negeri dan hubungan dengan negara lain, pertumbuhan permintaan akan kendaraan roda empat, proyeksi pasar ekspor, persaingan antara ATPM dalam pangsa pasar otomotif, isu lingkungan dan hubungan dengan masyarakat sekitar, hubungan dengan asosiasi, serta loyalitas pelanggan semuanya merupakan peluang. Sementara itu, situasi politik dalam negeri, kebijakan pemerintah terkait izin impor, kebijakan pemerintah tentang PMA pada skala usaha IKM, fluktuasi nilai tukar, pertumbuhan ekonomi, serta perubahan dalam tren IKM berbasis teknologi semuanya teridentifikasi sebagai ancaman bagi PT PQR. 


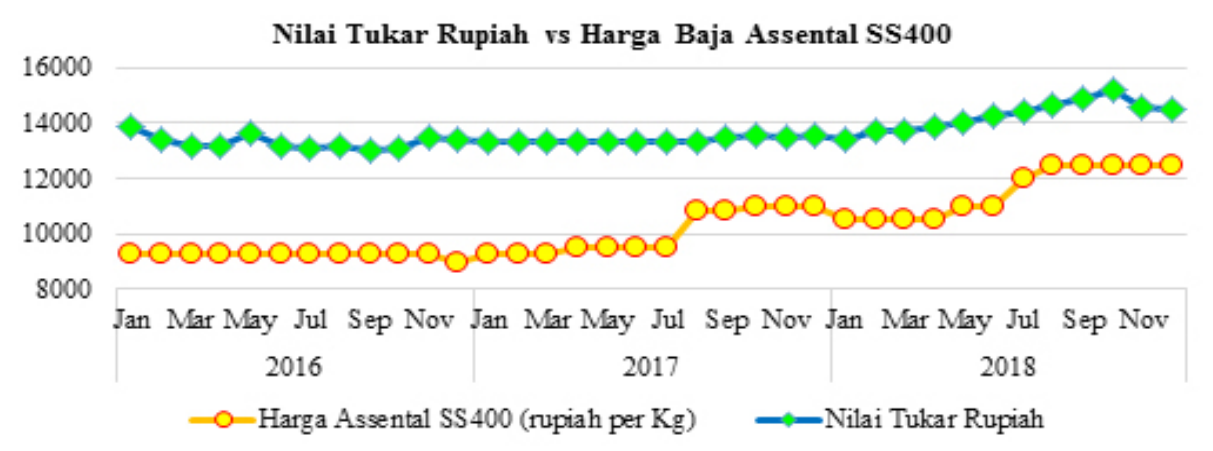

Gambar 2. Nilai tukar rupiah vs harga baja Assental SS400 pada 2016-2018

\section{Kondisi Internal PT PQR}

PT PQR memasuki industri komponen otomotif mulai tahun 2012 sebagai Tier-3 dan saat ini membuat 12 jenis produk komponen otomotif untuk pelanggannya di Tier-2. PT PQR memiliki 2 fasilitas pabrik di daerah Cibubur, dan sangat strategis karena dekat dengan akses jalan arteri dan berbagai jalur tol, selain juga dekat dengan lokasi para pelanggannya sehingga diuntungkan atas biaya transportasi yang lebih rendah. Fasilitas pabrik cukup lengkap dengan layout yang memadai untuk mendukung alur produksi. Proses produksi melalui tahapan pemotongan, penggerindaan dan penghalusan, penekukan, pemeriksaan akhir, diakhiri dengan pengepakan untuk lalu dikirim ke pelanggan. Proses pemotongan masih menggunakan mesin konvensional sehingga risiko kecelakaan cukup tinggi. Sejak tahun 2012 telah terjadi kecelakaan kerja sebanyak 4 kali, dengan yang terakhir terjadi pada bulan Januari 2018. Aspek keselamatan kerja inilah yang menjadi salah satu kelemahan bagi perusahaan.

Struktur organisasi PT PQR masih sederhana, terdiri dari seorang Presiden Direktur merangkap jabatan sebagai Direktur Operasional dan menjalankan fungsi Engineering serta Customer Support, Direktur Finance \& Accounting, dan 2 orang Kepala Pabrik. Terlihat beberapa fungsi dijalankan oleh hanya satu orang, sehingga menjadi penyebab tidak maksimalnya peranan yang dijalankan. Jumlah karyawan pada tahun 2018 adalah 35 orang, terdiri dari 32 orang pria dan 3 orang wanita, dengan $80 \%$ karyawannya hanya tamatan SMP, sisanya SMA (8,6\%), Diploma (5,7\%), dan Sarjana $(5,7 \%)$. Kondisi ini menunjukan keterbatasan dalam kualitas sumber daya manusia dengan menggunakan tenaga kerja yang tidak terlatih dan tidak memiliki keahlian. Kualitas SDM yang rendah menjadi salah satu kelemahan PT PQR, tercermin dari target produktivitas yang tidak tercapai dikarenakan rendahnya motivasi dan kedisiplinan operator-operator produksi.

Untuk memproduksi 100 ribu hingga 140 ribu komponen per bulan, PT PQR membutuhkan bahan baku kawat baja sekitar 60 ton per bulannya yang didapat dari 3 pemasok utama meski variasi harga dan kualitasnya berbeda-beda. Terbatasnya jumlah pemasok bahan baku untuk kawat baja membuat PT PQR kesulitan mempertahankan harga beli material. PT PQR juga tidak memiliki strategi khusus untuk menjaga persediaan dalam jumlah aman, meskipun terjadi fluktuasi permintaan dari pelanggan. Kesulitan dalam mendatangkan bahan baku dengan kualitas yang stabil disebutkan oleh manajemen PT PQR sebagai penghambat utama terhadap strategi penyimpanan tersebut. Saat ini kebanyakan bahan baku didapat dari impor, karena material produksi domestik tidak memenuhi standar kualitas yang dibutuhkan.

Kinerja produktivitas pada tahun 2018 belum dapat memenuhi permintaan pelanggan. Rata-rata rata pencapaian produktivitasnya hanya $64,98 \%$ dari target harian sebesar 8.400 buah. Salah satu penyebab adalah tingkat kehadiran operator produksi yang cukup rendah, dengan rata-rata 77,38\% untuk tahun 2018. Di sisi lain target kualitas justru tercapai dengan adalah 295 part-per-million (ppm) terhadap target 300 ppm, meski dengan usaha lebih besar dengan menambahkan tahapan pemeriksaan kualitas di setiap mesin dan sebelum pengepakan. Ketepatan jumlah pengiriman rata-rata tahun 2018 adalah $80,11 \%$, masih jauh di bawah target minimum 95\%. PT PQR juga tidak memiliki persediaan produk jadi (Finished Goods) untuk mengantisipasi kenaikan permintaan. 
Kinerja keuangan PT PQR dalam 5 tahun terakhir menunjukkan fluktuasi dalam hal pendapatan dan keuntungan. Tabel 2 menunjukkan tingkat pendapatan dalam periode 2013-2018. Pada tahun 2018 terdapat kenaikan pendapatan hingga 20\% dibandingkan tahun sebelumnya yang dipicu oleh kenaikan permintaan kendaraan roda empat dalam satu tahun terakhir ini.

Sementara Tabel 3 menunjukkan tingkat keuntungan dalam periode 2013-2018. Pada tahun 2018 terlihat keuntungan meningkat sebesar $16,67 \%$ dibandingkan tahun sebelumnya. Meski demikian, masih terlihat tren naik dan turunnya pendapatan maupun keuntungan terjadi secara bergantian di setiap tahunnya sehingga strategi bisnis untuk tahun 2019 menjadi sangatlah penting.

\section{Alternatif Strategi PT PQR}

Berdasarkan analisis faktor strategis internal, hasil perhitungan IFE didapat total skor 2,346 seperti diperlihatkan pada Tabel 4. Mengacu kepada David (2013), angka ini mengindikasikan perusahaan kurang memilikikemampuandalammeminimalisasikelemahan yang ada. Hal ini dapat terlihat dari keterulangan masalah yang dihadapi, khususnya terkait produktivitas rendah, kedisiplinan karyawan, dan pengiriman tidak tepat waktu. PT PQR dapat menerapkan prinsip PlanDo-Check-Act dari siklus Deming dalam penelusuran masalah dan pencarian solusi agar bisa mencegah keterulangan masalah yang terjadi (Liker, 2014).

Tabel 2. Pendapatan PT PQR periode 2013-2018

\begin{tabular}{lcccccc}
\hline Tahun & 2013 & 2014 & 2015 & 2016 & 2017 & 2018 \\
\hline Target (dalam juta rupiah) & 14000 & 16000 & 11000 & 11000 & 10000 & 11000 \\
Pencapaian (dalam juta rupiah) & 13500 & 11500 & 10000 & 10500 & 10000 & 12000 \\
Pertumbuhan tahun ke tahun (dalam persen) & & $-14,81 \%$ & $-13,04 \%$ & $5,00 \%$ & $-4,76 \%$ & $20,00 \%$ \\
\hline
\end{tabular}

Tabel 3. Keuntungan PT PQR periode 2013-2018

\begin{tabular}{lcccccc}
\hline Tahun & 2013 & 2014 & 2015 & 2016 & 2017 & 2018 \\
\hline Target (dalam juta rupiah) & 1400 & 1600 & 1100 & 1100 & 1000 & 1100 \\
Pencapaian (dalam juta rupiah) & 1300 & 1200 & 1100 & 1000 & 1200 & 1400 \\
Pertumbuhan tahun ke tahun (dalam persen) & & $-7,69 \%$ & $-8,33 \%$ & $-9,09 \%$ & $20,00 \%$ & $16,67 \%$ \\
\hline
\end{tabular}

Tabel 4. Matriks IFE untuk PT PQR

\begin{tabular}{|c|c|c|c|c|c|}
\hline Faktor Internal & $\begin{array}{c}\text { Kekuatan (S) / } \\
\text { Kelemahan (W) }\end{array}$ & Rating & Bobot & $\begin{array}{c}\text { Skor } \\
\text { (Rating X Bobot) }\end{array}$ & Rank \\
\hline Kapasitas produksi & $\mathrm{S}$ & 2,75 & 0,0861 & 0,2367 & S3 \\
\hline Kualitas produk & $\mathrm{S}$ & 3 & 0,1099 & 0,3297 & $\mathrm{~S} 1$ \\
\hline Citra perusahaan baik & S & 3,25 & 0,0568 & 0,1845 & S5 \\
\hline Harga jual produk bersaing & $\mathrm{S}$ & 3,5 & 0,0769 & 0,2692 & $\mathrm{~S} 2$ \\
\hline Kondisi keuangan baik & $\mathrm{S}$ & 3,25 & 0,0513 & 0,1667 & S6 \\
\hline Lokasi perusahaan strategis & $\mathrm{S}$ & 3,75 & 0,0330 & 0,1236 & S7 \\
\hline Biaya produksi efisien & $\mathrm{S}$ & 3 & 0,0641 & 0,1923 & S4 \\
\hline K3 & $\mathrm{W}$ & 1,5 & 0,1026 & 0,1538 & W2 \\
\hline Produktivitas rendah & $\mathrm{W}$ & 1,75 & 0,1209 & 0,2115 & W1 \\
\hline Kualitas SDM rendah & $\mathrm{W}$ & 1,25 & 0,1154 & 0,1442 & W3 \\
\hline Akses pasokan terbatas & $\mathrm{W}$ & 2 & 0,0549 & 0,1099 & W4 \\
\hline Jaringan pemasaran terbatas & $\mathrm{W}$ & 2 & 0,0385 & 0,0769 & W6 \\
\hline Pengiriman tak tepat waktu & W & 1,5 & 0,0659 & 0,0989 & W5 \\
\hline Penguasaan teknologi & $\mathrm{W}$ & 2 & 0,0238 & 0,0476 & W7 \\
\hline Total & & & & 2,346 & \\
\hline
\end{tabular}


Berdasarkan analisis faktor strategis eksternal, matriks EFE mendapat total skor 2,178, seperti diperlihatkan pada Tabel 5, yang menandakan PT PQR memiliki kemampuan rata-rata dalam merespon situasi eksternal yang ada, termasuk merespon peluang dan ancaman (David, 2013). Pertumbuhan permintaan kendaraan, persaingan antar ATPM serta loyalitas pelanggan adalah peluang-peluang yang paling dikenali, sementara fluktuasi nilai tukar dan kebijakan pemerintah terkait izin impor adalah ancaman terbesar yang dirasakan sebagai tekanan eksternal.
Kombinasi antara Matriks IFE dan Matriks EFE Intensitas dipetakan dengan menggunakan Matriks IE. Pada Gambar 3 diperlihatkan posisi PT PQR berada pada kuadran V (IFE 2,346; EFE 2,178) dan rekomendasi manajemen strategi bagi PT PQR adalah pertahankan dan pelihara (hold and maintain). Dua strategi yang direkomendasikan pada posisi ini adalah strategi penetrasi pasar dan pengembangan produk, dengan produk baru atau modifikasi produk yang sudah ada (David, 2013).

Tabel 5. Matriks EFE untuk PT PQR

\begin{tabular}{|c|c|c|c|c|c|}
\hline Faktor Eksternal & $\begin{array}{c}\text { Kekuatan (S) / } \\
\text { Kelemahan (W) }\end{array}$ & Rating & Bobot & $\begin{array}{c}\text { Skor } \\
\text { (Rating X Bobot) }\end{array}$ & Rank \\
\hline Politik luar negeri & $\mathrm{O}$ & 2,5 & 0,0612 & 0,1531 & $\mathrm{O} 4$ \\
\hline Pertumbuhan permintaan & $\mathrm{O}$ & 2,75 & 0,0993 & 0,2730 & $\mathrm{O} 1$ \\
\hline Proyeksi pasar ekspor & $\mathrm{O}$ & 1,375 & 0,0684 & 0,0940 & O8 \\
\hline Persaingan antar ATPM & $\mathrm{O}$ & 2,5 & 0,0630 & 0,1576 & $\mathrm{O} 3$ \\
\hline Isu lingkungan & $\mathrm{O}$ & 2,5 & 0,0392 & 0,0981 & $\mathrm{O} 7$ \\
\hline Hubungan masyarakat sekitar & $\mathrm{O}$ & 3,125 & 0,0422 & 0,1319 & O6 \\
\hline Hubungan dengan asosiasi & $\mathrm{O}$ & 3,125 & 0,0476 & 0,1486 & O5 \\
\hline Loyalitas pelanggan & $\mathrm{O}$ & 2,875 & 0,0910 & 0,2615 & $\mathrm{O} 2$ \\
\hline Situasi politik dalam negeri & $\mathrm{T}$ & 1,5 & 0,0684 & 0,1026 & T5 \\
\hline Kebijakan terkait Izin Impor & $\mathrm{T}$ & 2,125 & 0,0713 & 0,1516 & $\mathrm{~T} 2$ \\
\hline Kebijakan tentang PMA & $\mathrm{T}$ & 1,75 & 0,0612 & 0,1072 & $\mathrm{~T} 4$ \\
\hline Fluktuasi nilai tukar & $\mathrm{T}$ & 2,25 & 0,1165 & 0,2622 & $\mathrm{~T} 1$ \\
\hline Pertumbuhan ekonomi & $\mathrm{T}$ & 1,5 & 0,0927 & 0,1391 & $\mathrm{~T} 3$ \\
\hline Ancaman pendatang baru & $\mathrm{T}$ & 1,375 & 0,0410 & 0,0564 & T6 \\
\hline Tren IKM berbasis teknologi & $\mathrm{T}$ & 1,125 & 0,0369 & 0,0415 & $\mathrm{~T} 7$ \\
\hline Total & & & & 2,178 & \\
\hline
\end{tabular}

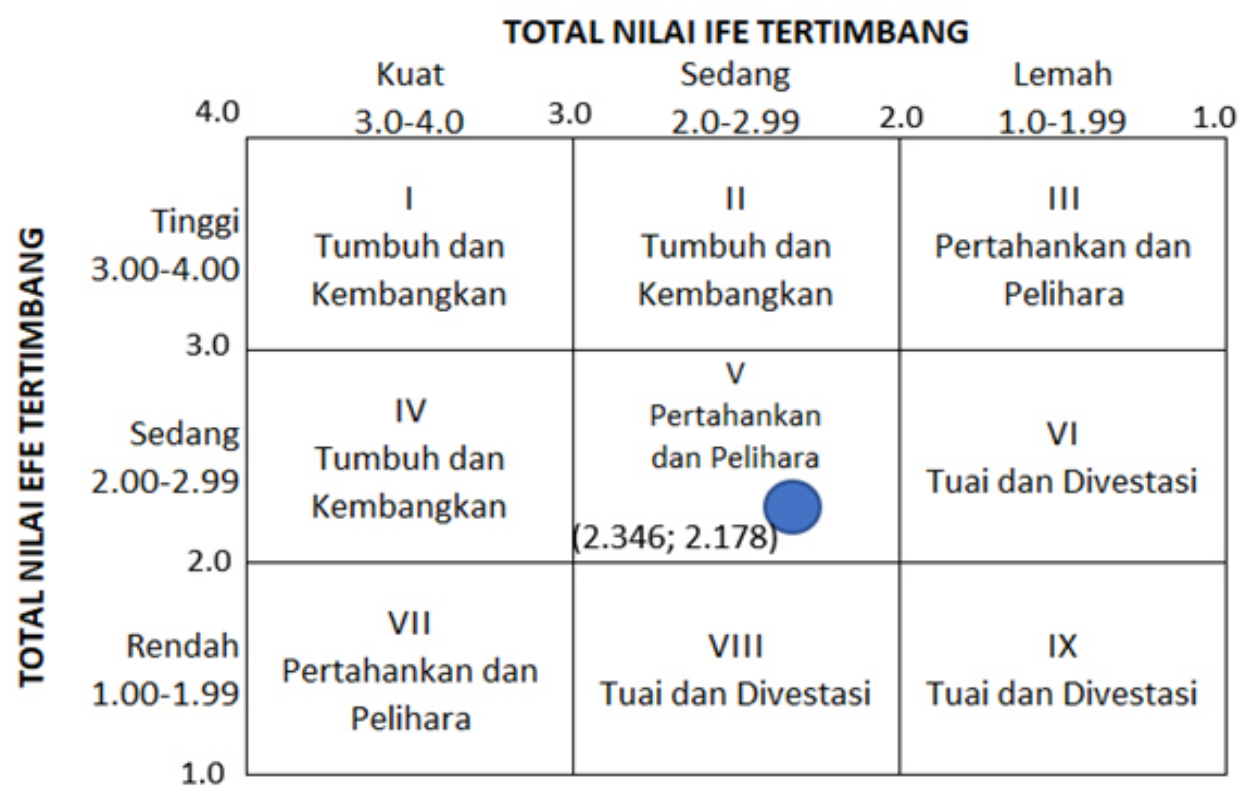

Gambar 3. Matriks Internal-Eksternal (IE) PT PQR 
Pada tahap pemaduan strategi melalui matriks TOWS, terdapat delapan alternatif strategi seperti terlihat pada Tabel 6. Kedelapan strategi alternatif tersebut dijabarkan sebagai berikut:

\section{Strategi pengembangan produk dengan diversifikasi}

Strategi untuk memanfaatkan kekuatan yang dimiliki untuk memaksimalkan peluang yang pertama adalah menjajaki potensi pelanggan potensial dari industri nonotomotif sebagai diversifikasi dari produk komponen otomotif yang dibuat saat ini. PT PQR memiliki ide untuk menyiapkan produk baru bagi industri furnitur yang juga membutuhkan bahan baku kawat baja, seperti contohnya rangka kursi dan sandaran kursi, bingkai foto, gantungan baju, dan aksesoris lainnya. Namun untuk itu tentunya manajemen PT PQR harus menyediakan sumber daya yang memadai untuk melakukan penelitian dan pengembangan produk baru ini.

\section{Perbaikan dalam manajemen produksi}

Strategi berikutnya dalam memanfaatkan kekuatan yang dimiliki untuk memaksimalkan peluang adalah dengan memperbaiki cara-cara pengelolaan produksi yang selama ini dilakukan oleh PT PQR, seperti meningkatkan efisiensi terhadap semua tahapan proses produksi dari mulai pengelolaan pesanan, pemesanan dan penerimaan bahan baku, perencanaan dan penjadwalan produksi yang lebih baik, hingga penentuan jadwal pengiriman produk. Keuntungan yang bisa didapat adalah menekan pemakaian tenaga listrik, menekan pembayaran jam lembur yang tidak direncanakan akibat ketidakpastian jadwal produksi, serta menekan biaya klaim atas keterlambatan pengiriman produk.

\section{Tabel 6. Matriks TOWS untuk PT PQR}

\begin{tabular}{|c|c|c|}
\hline & $\begin{array}{l}\text { Kekuatan (S) } \\
\text { 1. Kualitas produk } \\
\text { 2. Harga jual produk bersaing } \\
\text { 3. Kapasitas produksi } \\
\text { 4. Biaya produksi efisien } \\
\text { 5. Citra perusahaan baik } \\
\text { 6. Kondisi keuangan baik } \\
\text { 7. Lokasi perusahaan strategis }\end{array}$ & $\begin{array}{l}\text { Kelemahan }(\mathrm{W}) \\
\text { 1. Produktivitas rendah } \\
\text { 2. K3 } \\
\text { 3. Kualitas SDM rendah } \\
\text { 4. Akses bahan baku terbatas } \\
\text { 5. Pengiriman tidak tepat waktu } \\
\text { 6. Jaringan pemasaran terbatas } \\
\text { 7. Penguasaan teknologi rendah }\end{array}$ \\
\hline $\begin{array}{l}\text { Peluang }(\mathrm{O}) \\
\text { 1. Pertumbuhan permintaan } \\
\text { 2. Loyalitas pelanggan } \\
\text { 3. Persaingan antara ATPM } \\
\text { 4. Politik luar negeri } \\
\text { 5. Hubungan dengan asosiasi } \\
\text { 6. Hubungan masyarakat } \\
\text { 7. Isu lingkungan } \\
\text { 8. Proyeksi pasar ekspor }\end{array}$ & \begin{tabular}{l}
\multicolumn{1}{c}{ Strategi SO } \\
Diversifikasi dengan produk furnitur \\
$(\mathrm{S} 1,2,3,4,6-\mathrm{O} 2,3,4,8)$ \\
Perbaikan manajemen produksi \\
$(\mathrm{S} 2,3,4-\mathrm{O} 2,3,4,8)$
\end{tabular} & $\begin{array}{l}\text { Strategi WO } \\
\text { Pengembangan Sumber Daya Manusia } \\
(\mathrm{W} 1,2,3,5,7-\mathrm{O} 2,3,8) \\
\text { Mengembangkan pemasaran ke ATPM } \\
\text { baru dan Industri furnitur (W6, } 7 \\
\text {-O2,3,8) }\end{array}$ \\
\hline $\begin{array}{l}\text { Ancaman }(\mathrm{T}) \\
\text { 1. Fluktuasi nilai tukar } \\
\text { 2. Kebijakan izin impor } \\
\text { 3. Pertumbuhan ekonomi } \\
\text { 4. Kebijakan tentang PMA } \\
\text { 5. Situasi politik dalam negeri } \\
\text { 6. Ancaman pendatang baru } \\
\text { 7. Tren IKM berbasis teknologi }\end{array}$ & $\begin{array}{l}\text { Strategi ST } \\
\text { Penerapan manajemen Mutu } \\
(\mathrm{S} 1,4,5,6,-\mathrm{T} 1,2,6,7) \\
\text { Investasi-mesin berkapasitas lebih } \\
\text { tinggi } \\
(\mathrm{S} 3,4,6-\mathrm{T} 6,7)\end{array}$ & $\begin{array}{l}\text { Strategi WT } \\
\text { Perbaikan pengelolaan inventori (W4, } \\
5-\mathrm{T} 1,2,3,5) \\
\text { Peningkatan Standar Operasi Produksi } \\
(\mathrm{SOP}) \\
(\mathrm{W} 1,3,5,7-\mathrm{T} 6,7)\end{array}$ \\
\hline
\end{tabular}




\section{Strategi Pengembangan Sumber Daya Manusia}

Strategi berikutnya ditujukan mengatasi kelemahan yang dimiliki untuk memaksimalkan peluang dari lingkungan eksternal. SDM saat ini memiliki kontribusi atas tidaktercapainya target produktivitas. Oleh karena itu, strategi dalam pengembangan SDM menjadi penting. Tinjauan atas struktur organisasi PT PQR juga harus dilakukan agar setiap pimpinan dapat lebih fokus pada tugas dan tanggungjawabnya. Pelatihan dan pengembangan, kedisiplinan dan motivasi kerja perlu ditingkatkan, selain juga memberikan tunjangantunjangan untuk mengiringi penghargaan perusahaan bagi karyawan-karyawan yang berkontribusi besar memajukan perusahaan.

\section{Strategi pengembangan pasar}

Strategiberikutnyayang ditujukanmengatasikelemahan untuk memaksimalkan peluang adalah dengan strategi pengembangan pasar dengan menargetkan pemasaran ke ATPM baru, diantaranya adalah merek Wuling, serta lebih serius mempersiapkan diri untuk memasuki industri furnitur sebagai salahsatu alternatif pasar baru. PT PQR dapat memanfaatkan kapasitas produksi tersedia dan menjadikan kualitas produk sebagai citra perusahaan untuk memasuki kedua pasar potensial tersebut.

\section{Penerapan Manajemen Mutu}

Dua strategi berikutnya dirumuskan untuk memanfaatkan kekuatan PT PQR dalam menghindari ancaman dari lingkungan eksternal. Berkaitan dengan semakin tingginya ancaman pendatang-pendatang baru dalam industri komponen otomotif, PT PQR dapat memanfaatkan kualitas produk dan citra perusahaan yang baik, serta kondisi keuangan yang sehat dan harga jual yang bersaing untuk meningkatkan nilai perusahaannya dengan menerapkan manajemen mutu, seperti dengan mengupayakan Sertifikasi ISO9001. Melalui penerapan prinsip-prinsip manajemen mutu, PT PQR berharap bisa memperbaiki seluruh metode kerja dari seluruh karyawan baik manajemen maupun karyawan produksi sehingga pada akhirnya dapat memperbaiki kualitas produk maupun kualitas proses yang dijalankannya.

\section{Strategi Investasi- mesin berkapasitas lebih tinggi}

Strategi alternatif berikutnya untuk untuk memanfaatkan kekuatan dalam menghindari ancaman dari lingkungan eksternal adalah dengan melakukan investasi mesin dan peralatan baru. Terlebih bagi PT PQR yang memiliki kondisi keuangan dan permodalan yang baik menjadikan ide pengenalan mesin CNC menjadi sangat memungkinkan. Hal tersebut dapat juga dilakukan dengan biaya yang lebih sedikit bila mesin CNC tersebut bukanlah baru, tetapi rekondisi dari mesin bekas yang didapat dari perusahaan manufaktur lainnya. Dengan penambahan mesin $\mathrm{CNC}$ maka kapasitas produksi akan bertambah, kebutuhan tenaga kerja terampil bertambah dan di sisi lain menurunkan ketergantungan akan tenaga kerja tidak terampil, karena perbandingan mesin konvensional dengan $\mathrm{CNC}$ bisa mencapai rata-rata 4 kali lebih efisien dalam hal waktu siklus kerja (Cycle-time).

\section{Perbaikan pengelolaan inventori}

Dua alternatif strategi yang terakhir adalah bentuk strategi defensif yang ditujukan untuk meminimalkan kelemahan untuk menghindari ancaman eksternal. Kelemahan dalam rendahnya produktivitas dan ketepatan waktu pengiriman bersumber pada kelemahan dalam keterbatasan pasokan bahan baku. Sementara ancaman dari fluktuasi nilai tukar, kebijakan impor, pertumbuhan ekonomi, serta persaingan yang semakin tinggi dalam mendapatkan bahan baku membuat PT PQR harus melakukan perbaikan dalam pengelolaan pasokan kawat baja.

PT PQR bisa memulainya dengan melakukan strategy Safety Stock dalam mengatasi ketidakpastian dalam pasokan sehingga mampu menjamin keberlangsungan produksinya pada kurun waktu tertentu. Tingkat persediaan aman ini bisa dihitung secara statistik berdasarkan pengalaman perusahaan selama mendapatkan pasokan kawat baja dari para pemasoknya. Upaya menambah pemasok potensial harus terus dilakukan agar tidak memiliki ketergantungan yang sangat tinggi seperti yang terjadi saat ini.

\section{Peningkatan Standar Operasi Produksi (SOP)}

Alternatif strategi berikutnya dalam meminimalisasi kelemahan untuk mengatasi ancaman adalah dengan memperbanyak standar-standar kerja bagi seluruh karyawan yang terlibat dalam proses produksi. Telah 
diketahui bahwa PT PQR memiliki produktivitas yang masih rendah, disebabkan oleh kualitas SDM dan penguasaan teknologinya yang juga rendah. Peningkatan Standar Operasi Produksi (SOP) akan menjadi strategi dengan biaya rendah untuk mengatasi kelemahan tersebut dan menghindari ancaman akan semakin sesaknya persaingan IKM komponen otomotif, berlomba-lomba dalam penguasan teknologi lebih tinggi. Hal ini juga merupakan bagian dari strategi untuk meningkatkan setidaknya dua dari empat kemampuan teknologi perusahaan yang dijabarkan oleh Lembaga Ilmu Pengetahuan Indonesia (1993), yaitu kemampuan operatif dan kemampuan akuisitif atau rekayasa.

\section{Prioritas Strategi PT PQR}

Berdasarkan analisis dan pengolahan data menggunakan Matriks QSPM dengan melibatkan manajemen PT PQR atas delapan alternatif strategi maka strategi pengembangan pasar dengan memasuki pasar ATPM baru dan industri furnitur adalah prioritas utama dengan total attractive score 6,33 dan strategi pengembangan produk dengan diversifikasi produk furnitur sebagai prioritas kedua, dengan total attractive score 5,77. Dengan metode Nominal Group Technique dibuatlah rencana tindakan jangka pendek maupun jangka panjang. Diantara rencana tindakan jangka pendek adalah melakukan pendekatan ke ATPM Wuling, memperluas market search untuk produk after sales yang saat ini masih bersifat One Time Only, menyiapkan prototipe untuk produk-produk furnitur yang sedang ditawarkan oleh pelanggan dan perencanaan proses produksi untuk produk furnitur, melakukan strategy Safety Stock, memperbaiki penjadwalan produksi dan jadwal pengiriman produk ke pelanggan. Sementara untuk jangka panjang adalah mengupayakan Sertifikasi ISO9001, investasi satu unit Mesin CNC untuk meningkatkan produktivitas, membuat program pelatihan, memperbanyak prosedur dan standar kerja, merumuskan Peraturan Perusahaan dan Kontrak Kerja, serta meningkatkan program penghargaan karyawan.

\section{Implikasi Manajerial}

Berdasarkan rencana tindakan yang telah disepakati, terutama yang menjadi strategi prioritas untuk dapat meningkatkan daya saing dalam bisnis komponen otomotif, maka PT PQR perlu menyediakan sumber daya yang dibutuhkan, baik berupa sumber daya manusia, waktu, maupun pembiayaan untuk menerapkan rencana-rencana tersebut. Hal ini bisa dimulai dengan melakukan program pemasaran yang lebih agresif terhadap perusahaan-perusahaan yang sudah menjadi rantai pasok bagi ATPM baru juga pasar after market, serta meningkatkan pendekatan terhadap calon pelanggan potensial yang begerak dalam bidang retail produk furnitur untuk pelanggan baru yang saat ini menunggu produk-produk prototype yang akan ditawarkan.

Di sisi lain persiapan produk-produk baru bagi industri furnitur mengharuskan PT PQR untuk mendukung tim perencanaan dan desain produk, yang berada di luar sumber daya yang dimiliki perusahaan saat ini. PT PQR dapat mempertimbangkan untuk melakukan perekrutan tenaga ahli, atau melakukan kerja sama dengan pihak ketiga untuk membeli desain produknya saja. Produkproduk furnitur membutuhkan keunikan dan karakterkarakter khas yang sangat bervariasi sehingga aspek desain akan menjadi keunggulan kompetitifnya. Oleh karena itu, PT PQR harus benar-benar serius mempersiapkan sumber daya yang dibutuhkan untuk memasuki industri ini.

\section{KESIMPULAN DAN SARAN}

\section{Kesimpulan}

Analisis Eksternal mengidentifikasi pertumbuhan permintaan akan kendaraan roda empat, loyalitas pelanggan, dan persaingan antara ATPM sebagai tiga peluang utama. Sementara itu, fluktuasi nilai tukar dan kebijakan pemerintah terkait izin impor adalah ancaman utama. Analisis internal menghasilkan kualitas produk, harga jual yang bersaing, dan kapasitas produksi sebagai tiga kekuatan utama. Produktivitas rendah, aspek K3 ditandai dengan kecelakaan kerja, dan kualitas SDM adalah tiga kelemahan utama.

PT PQR dalam posisi strategi pertahankan dan pelihara (hold and maintain) dan alternatif strategi bagi yang menjadi pilihan yaitu strategi pengembangan produk dengan diversifikasi produk furnitur, dan pengembangan pasar dengan memasuki pasar ATPM baru dan industri furnitur, perbaikan dalam manajemen produksi, pengembangan SDM, penerapan manajemen mutu, investasi mesin berkapasitas lebih tinggi, pengelolaan inventori, dan peningkatan Standar Operasi Produksi (SOP). 
Strategi pengembangan pasar dengan memasuki pasar ATPM baru dan industri furnitur adalah prioritas utama dan strategi pengembangan produk dengan diversifikasi produk furnitur sebagai prioritas kedua, dengan berbagai rencana tindakan yang telah ditetapkan untuk menerapkan strategi tersebut pada tahun 2019 hingga 2020.

\section{Saran}

PT PQR adalah salahsatu IKM yang mampu bertahan sejauh ini sebagai pelaku Tier 3 bagi rantai pasok industri otomotif meskipun mengalami berbagai tantangan bisnis yang besar, atas dasar kekuatan yang dimiliki yaitu kualitas produk, sebagai kompetensi inti yang membuat pelanggannya loyal. Oleh karena itu, kekuatan internal ini harus terus dipertahankan untuk mencapai tujuan-tujuan strategisnya di masa yang akan datang. Saran bagi penelitian selanjutnya adalah menganalisa pengaruh IKM-IKM bermodalkan PMA dan menganalisa seberapa besar pengaruhnya dalam persaingan di industri komponen otomotif, serta dalam kaitannya terhadap kebijakan-kebijakan pemerintah dalam upaya melindungi IKM-IKM lokal dan meningkatkan iklim usaha yang lebih baik sehingga IKM-IKM lokal dapat memberikan kontribusi yang lebih besar terhadap peningkatan industri otomotif di Indonesia.

\section{DAFTAR PUSTAKA}

Amrina E, Yusof SM. 2010. Manufacturing performance evaluation tool for Malaysian automotive small and medium-sized enterprises. International Journal of Business and Management Science 3(2):195-213.

Anggoro Y. 2015. Automotive and logistics clusters to drive economic competitiveness in Java Indonesia [disertasi]. Charlotte: University of North Carolina.

Baharudin N, Jusoh R. 2015. Target Cost Management (TCM): a case study of an automotive company. Procedia-Social and Behavioral Sciences 2015(172): 525-532. https://doi.org/10.1016/j. sbspro.2015.01.398

Block W, Barnett W II. 2009. Monopsony theory. American Review of Political Economy 7(2): 67-109.

David FR. 2013. Strategic Management; Concept and Cases. 14th ed. New Jersey (US): Pearson
Education Inc.

Dianawati A. 2003. Formulasi Strategi PT Safira Tumbuh Berkembang [tesis]. Bogor(ID): Institut Pertanian Bogor.

Feil P, Yook KY, Kim IW. 2004. Japanese target costing: a historical perspective. International Journal of Strategic Cost Management 2004 Spring: 1019.

[Gaikindo] Gabungan Industri Kendaraan Bermotor Indonesia. 2017. Auto production by brand 2010-2016. https://www.gaikindo.or.id/autoproduction-by-brand-2010-2016/ [2017 Nov $20]$.

Gupta, Abhishek. 2013. Environment \& PEST analysis: an approach to external business environment. International Journal of Modern Social Sciences 2(1): 34-43.

Hambrick CD, Fredrickson WJ. 2005. Are you sure you have a strategy. Academy of Management Executive 19(4): 51-62. https://doi.org/10.5465/ ame.2005.19417907.

Huge J, Mukherjee N. 2018. The nominal group technique in ecology \& conservation. British Ecological Society 14(9): 33-41. https://doi. org/10.1111/2041-210X.12831.

Hoskisson RE, Hitt MA, Ireland RD, Harison JS. 2008. Competing for Advantage. 2nd ed. Mason: Thomson South-Western.

Katuruni IR. 2015. Perencanaan strategi bisnis spare parts otomotif berbahan dasar karet (studi kasus: CV Regina Eka Pratiwi) [tesis]. Bogor: Institut Pertanian Bogor.

[Kemendag] Kementrian Perdagangan Republik Indonesia. 2014. Perkembangan komponen otomotif di Indonesia. Warta Ekspor 5(7).

[Kemenperin] Kementrian Perindustrian. 2017. Industri Otomotif Berkontribusi Besar Bagi Ekonomi Nasional.http://www.kemenperin.go.id/ artikel/17466/Industri-Otomotif-BerkontribusiBesar-Bagi-Ekonomi-Nasional.[2018 Feb 11].

[Kemenperin] Kementrian Perindustrian. 2016. ATPM Sodorkan Peluang ke IKM Otomotif. http:// www.kemenperin.go.id/artikel/6012/ATPMSodorkan-Peluang-ke-IKM-Otomotif [2018 Feb $11]$.

Kinnear TC, Taylor JR. 1996. Marketing Research: an Applied Approach. 5th ed. New York: McGrawHill.

Laosirihongthong T, Dangayach GS. 2005. A comparative study of implementation of manufacturing strategies in thai and indian 
manufacturing companies. Journal of Manufacturing Systems 24(2):131-143. https:// doi.org/10.1016/S0278-6125(05)80013-5.

Lawrence WW. 2012. Coping with external pressures: A note on SME Strategy. Social and Economic Studies 61(1): 161-170.

Leitner, KH, \& Gudenberg S. 2010. Generic strategies and firm performance in SMEs: A longitudinal study of Austrian SMEs. Small Business Economics (35):169-189.https://doi. org/10.1007/s11187-009-9239-x.

Liker JK. 2014. The Toyota Way: 14 Management Principles From the world's Greatest Manufacturer. New York: McGraw-Hill.

Lin C. 2014. The japanese automotive industry: recent developments and future competitive outlook. [thesis]. Michigan: University of Michigan.

Monden Y, Hamada K. 1991. Target costing and Kaizen costing in Japanese automobile companies. Journal of Management Accounting Research 3(1):19-31.

Nisipeanu E. 2013. Assessment of small and mediumsized enterprises' competitiveness level based on direct interview. Research and Science Today 3(1):177-187.

Nunez MG. 2007. Strategies for leading change in the automotive industry [disertation]. California: Pepperdine University.

Porter ME. 2008. The five competitive forces that shape strategy. Harvard Business Review 86(1): 78-93.

Purwaningsih R, Kusuma PD. 2015. Analisis faktorfaktor yang memengaruhi kinerja Usaha Kecil dan Menengah (UKM) dengan metode Structural Equation Modeling [tesis] Semarang: Universitas Diponegoro.

Purwantoro. 2016. Analisis strategi bersaing dan pengukuran kinerja dengan pendekatan resource base view perusahaan komponen otomotif Indonesia [tesis]. Bogor: Institut Pertanian Bogor.

Rahman, Fatmasari L, Mangkusubroto K, Sunitiyoso Y. 2012. Strategy development of pt xyz a startup technology company. The Indonesian Journal of Business Administration 1(1):6-11.

Samitowska W. 2011. Barriers to the development of entrepreneurship demonstrated by micro, small and medium enterprises in poland.
Economics \& Sociology 4(2): 42-49. https://doi. org/10.14254/2071-789X.2011/4-2/5.

Schonberger RJ. 1982. Japanese Manufacturing Techniques. New York: Free Press.

Setyawan AA, Muzakan I, Wajdi FM, Syamsudin, Nugroho PS. 2015. An assessment of sme competitiveness in Indonesia. Journal of Competitiveness 7(1): 60-74. https://doi. org/10.7441/joc.2015.02.04.

Smitka MJ. 1989. Competitive ties: Subcontracting in the Japanese automotive industry [disertation]. New Haven: Yale University.

Suprihatini R, Maarif S. 1999. Peran Teknologi terhadap keunggulan bersaing dan strategi peningkatan penguasaan teknologi di industry the Indonesia. Forum Penelitian Agro Ekonomi 17(1): 49-65. https://doi.org/10.21082/fae.v17n1.1999.49-65.

Takeishi A, Noro Y. 2017. Keiretsu divergence in the Japanese automotive industry. CEAFJP Discussion paper 7(04): 121-149.

Tambunan T. 2008. SME development in Indonesia: do economic growth and government supports matter? SSRN Electronic Journal 4(2): 111-133. https://doi.org/10.2139/ssrn.1218922.

Vermaak KJ, Steyn J. 2014. Innovation strategy complexity and scope in automotive component manufacturing in developing economies. Engineering Management Journal 26(3):36-44. https://doi.org/10.1080/10429247.2014.114320 18.

Vanalle RM, Salles JAA. 2012. Buyer-supplier relationships in the Brazilian automotive industry. African Journal of Business Management 6(31): 9056-9064. https://doi.org/10.5897/ AJBM12.654.

Vidiansyah R. 2013. Perencanaan arsitektur strategik usaha budidaya jamur tiram di PT Jamur Tiram Indonesia tahun 2012-2022 [tesis]. Bogor: Institut Pertanian Bogor.

Wheelen TL, Hunger JD. 2012. Strategic Management andBusiness PolicyToward GlobalSustainability. New Jersey: Pearson Education Inc.

Wicaksono P, Priyadi L. 2016. Decent work in global production network lessons learnt from the indonesian automotive sector. Journal of Southeast Asian Economies 33(1): 95-110. https://doi.org/10.1355/ae33-1f. 